\title{
Evaluation and analysis of gaseous emission in landfill area and estimation of its pollutants dispersion, (case of Rodan in Hormozgan, Iran)
}

\author{
Amirreza Talaiekhozani ${ }^{{ }^{*}}$, Somaye Bahrami ${ }^{2}$, Seyed Mohammad Javad Hashemi ${ }^{3}$, Sahand Jorfi $^{4,5}$ \\ ${ }^{1}$ Assistant Professor, Department of Civil Engineering, Jami Institute of Technology, Isfahan, Iran \\ ${ }^{2} \mathrm{PhD}$ Student of Environmental Engineering, School of Post Graduate, Islamic Azad University Branch of Bushehr, Bushehr, Iran \\ ${ }^{3}$ M.Sc, Department of Civil Engineering, Jami Institute of Technology, Isfahan, Iran \\ ${ }^{4}$ Assistant Professor, Environmental Technologies Research Center, Ahvaz Jundishapur University of Medical Sciences, Ahvaz, Iran \\ ${ }^{5}$ Assistant Professor, Department of Environmental Health Engineering, School of Health, Ahvaz Jundishapur University of Medical \\ Sciences, Ahvaz, Iran
}

\begin{abstract}
Background: The biogases are the mixture of gases produced through the microbial decomposition of organic waste which are amply observed in the landfills. The main purpose of this study was to estimate the emission rates of landfill gases such as carbon dioxide, methane and non-methane organic compounds (NMOCs) in the solid waste landfill of Rodan city in Hormozgan province.

Methods: All the necessary information such as population, geographic and climate of Rodan city were collected. Solid waste analysis was then conducted. Afterward, the LandGEM software is used in this study for the purpose of estimation of total biogas, methane, carbon dioxide and NMOCs emission from Rodan's landfill.

Results: The analysis of results showed that only $24.18 \%$ of the produced waste in this city is perishable. The calculations indicate that the peak of biogas production which is equal to 420 tons per year would be achieved in the year 2019. The production rates of carbon dioxide and methane in the same year would be equal to 308 and 112 tons per year respectively. The pollutants transmittance calculations in the vicinity of the landfill revealed that the maximum pollutant concentration is within the maximum distance of $200 \mathrm{~m}$.

Conclusion: The results obtained in this study could be used for the purpose of design and installation of extraction or incineration equipment in the landfill of Rodan.

Keywords: Solid waste, Landfill, Biogas, Rodan city, LandGEM

Citation: Talaiekhozani A, Bahrami S, Hashemi SMJ, Jorfi S. Evaluation and analysis of gaseous emission in landfill area and estimation of its pollutants dispersion, (case of Rodan in Hormozgan, Iran). Environmental Health Engineering and Management Journal 2016; 3(3): 143-150. doi: 10.15171/EHEM.2016.13.
\end{abstract}

\section{Article History:}

Received: 8 June 2016 Accepted: 25 July 2016 ePublished: 19 August 2016

\section{Introduction}

In today's world, the waste compounds are addressed as environmental pollutants which would result in severe problems if not properly disposed. With this in mind, the waste disposal areas would play a vital role in the waste disposal networks which is the pivotal aspect of the general waste management strategy. The gas extraction equipment and energy consumption are presently the most significant component of the landfill areas $(1,2)$. The disposed waste in landfill areas would be subjected to a variety of biochemical and physical reaction which could lead to the production and emission of substantial amount of gaseous components and liquids. Among these gasses, carbon dioxide and methane have significant importance due to their greenhouse properties (3). The installation of necessary equipment for the extraction of these gasses is essential in order to prevent their release into the atmo- sphere (4).

Biogas is the mixture of gases produced through microbial decomposition of organic compounds in anaerobic conditions. Generally, the biogases are dominantly composed of 40\%-75\% methane and 15\%-50\% carbon dioxide in addition to little amounts of water vapor (5\%-10\%), hydrogen sulfide $(0.005 \%-2 \%)$, less than $6 \%$ halogenic hydrocarbon, less than $1 \%$ ammonium, less than $0.6 \%$ carbon monoxide, $0 \%-2 \%$ nitrogen and minimal amounts of non-methane organic compounds (NMOCs) $(5,6)$. Usually, for every ton of waste, about $250 \mathrm{~kg}$ of biogas is produced which can be consumed through extraction and treatment (7). Hajbagheri et al (5) introduced the LandGEM software and its applications in the calculation of the biogases production rates such as carbon dioxide, methane and NMOCs. Their evaluations revealed that the LandGEM software is a reliable and appropriate tool for the purpose 
of estimating a wide range of gaseous compounds. They have also investigated the effects of the waste composition on the estimation accuracy of LandGEM software (5). Results indicated that $60 \%$ of the produced biogas in landfills of Shiraz was methane which would be financially beneficial if extracted. Omrani et al (8) have also conducted another study by using the LandGEM software which illustrated that the emission rates of methane and carbon dioxide from the landfills of Shiraz are equal to 24 and $60 \mathrm{~m}^{3} / y$ respectively (8). Safari et al have also employed the LandGEM software to investigate the gases produced in the landfills of Mashhad. After the initial estimations, two disposal options which were incineration and energy production were investigated. The study results revealed that the environmental benefits would be significant despite high initial costs of energy production from methane (7). Zoghi and Ghavidel (4) estimated the rate of methane production in the municipal landfills by utilizing artificial neural networks. These researchers provided an estimation model for produced gases by considering parameters such as latex circulation and landfill properties. Mahvi and Rodbari (9) calculated the rate of produced biogases in the landfills of Shahrod using LandGEM software. The study results indicated that $488 \mathrm{~m}^{3}$ methane and $46 \mathrm{~m}^{3}$ carbon dioxide are released into the atmosphere from this landfill annually. Mahdipour et al (10) have also modeled the produced gasses in the landfills of Ahvaz, Abadan and Dezfol. They have concluded that these landfills possess high potentials for producing substantial amounts of methane. The main purpose of this study was to estimate the gas emission rates in the landfill including carbon dioxide, methane and NMOCs in the municipal waste landfill of Rodan city located in Hormozgan province. In the first step, the required information such as waste composition and production rates were investigated. Then LandGEM software, developed by the United States Environmental Protection Agency (USEPA), was employed to estimate the emission rates of the produced gases. Lastly, the Screen View software was used in modeling the biogas emission. The results obtained in this study are applicable for the purpose of design and installation of gas extraction systems in the landfill. The study results have also illustrated the pollutant range of motion in the atmosphere and their concentrations within various seasons.

\section{Methods}

Future population estimation

The population of Rodan city was calculated between years 2016 and 2019 by considering the present population of the city and the population growth coefficient using Eq.1:

$P_{n}=P_{0}(1+r)^{n}$

where, $P_{n}$ is the population in year n, $P_{0}$ is the population in the origin year, $r$ is the average population growth rate and $\mathrm{n}$ is the number of years.

Geographic and climatic characteristics of Rodan This study is conducted on the landfill of Rodan, Hor- mozgan province. Based on the capitation conducted in 2011, the city comprised a population of 118547 individuals. The landfill is situated $5 \mathrm{~km}$ away from the city. Based on the reports of Iranian climatology agency, the average precipitation within the course of 10 years in 2003 to 2013 is $208.12 \mathrm{~mL}$ per year and the average maximum temperature of the city is $39.3^{\circ} \mathrm{C}$ within the course of 10 years. Based on Talaiekhozani's report (11), the selection of existing coefficients and parameters in LandGems software including the methane production rate $(\mathrm{k})$ and methane production potential capacity (Lo) is dependent on the climate of the area under study.

The climate of an area is indicated by the aridity index. The aridity index is used as an indicator to determine the level of dryness of the climate at a specific area. Although there are several aridity indices, but majority of them are not applicable for Iranian climate. De Martonne method (Eq. 2) was selected as the most compatible aridity index for Iran climate among the different methods used to determine the aridity index (Eq. 2) (11).

$I=\frac{P}{(T+1)}$

where $I$ is the De Martonne dryness parameter, $T$ is the average annual temperature in ${ }^{\circ} \mathrm{C}$ and $P$ is the average annual precipitation in $\mathrm{mm}$. The results obtained from Eq. 2 are compared with Table 1 in order to determine the climate type.

\section{Waste analysis method}

All analysis was conducted by the municipal recycling agency of Rodan city in year 2012. The municipal authorities have attempted to obtain a set of samples from the city waste. Four waste transport trucks, with predetermined load capacity were selected for this purpose. These trucks dispose four loads of municipal wastes on a daily basis. The density of disposed waste is then determined in respect to its volume and weight. This process was repeated every month for a year. It is worth mentioning that no samples were obtained before and after holidays to insure the minimum possible error in sampling. A composite sample was also obtained in order to determine the quality and quantity of the solid waste including the percentage of perishable and non-perishable compounds, the percentage of organic and volatile organic matters and humidity which was based on standard methods (2).

Table 1. De Martonne dryness coefficient range and related climate type

\begin{tabular}{lc}
\hline Climate types & \multicolumn{1}{c}{} \\
\hline Dry & Smaller than 10 \\
Semi dry & 10 to 19.9 \\
Mediterranean & 20 to 23.4 \\
Semi humid & 24 to 27.9 \\
\hline Humid & 28 to 34.9 \\
\hline Intense humidity & Higher than 35 \\
\hline
\end{tabular}

Source: Reference 12. 
Evaluation of gas emission rate

The gas emission rate of the landfill was evaluated using LandGEM software. The LandGEM software is developed by the USEPA. LandGEM is an automated tool used in estimating total biogas, methane, carbon dioxide and NMOCs from municipal solid waste landfills (11). This software is utilized for estimation of gases emission based on either site-specific data or default parameters. LandGEM has two groups of default parameters known as specifically inventory defaults and Clean Air Act (CAA) defaults. The CAA defaults have been developed based on federal regulations for municipal solid waste landfills. The CAA defaults are utilized to determine if a specific landfill requires the control of gases emission or not. The inventory defaults have been developed based on emission factors in environmental protection agency (11). A first-degree equation is provided by the software in order to estimate the rate of the produced gases Eq. 3.

$Q_{C H 4}=\sum_{i=1}^{n} \sum_{j=0.1}^{1} K L_{0}\left[\frac{M_{i}}{10}\right] e^{-K t_{i j}}$

Where $Q_{C H 4}$ is the produced methane in the calculated year (cubic meter per year, $i$ is the step index in year, $n$ is the year of origin-first year of operation, $j$ is equal to 0.1 time increment in year, $K$ is reverse of years of methane productions, $L_{0}$ is the methane production potential in $\mathrm{cu}$ bic meter per ton, $M_{i}$ is the disposed waste mass in year $i$ in ton, and $t_{i j}$ is the age of the $j$ portion of the waste in the year $i$ within the operation year. The characteristics of the Rodan landfill were then fitted into the model according to Table 2 .

Results

Climate of Rodan

The Rodan's landfill is located in a plain area with hills and

vegetation such as mesquite, lotus and sorrel. Registered statistics of synoptic station in the course of 10 years from 2003 to 2013 were analyzed in order to determine the precipitation quantity of this region. Table 3 presents the average precipitation rates during various seasons of the year. The average annual precipitation was equal to 208.12 $\mathrm{mm}$. The average temperature of Rodan was $39.3^{\circ} \mathrm{C}$. Based on the De Martonne coefficient of 5, the climate classification is said to belong to a dry climate type. Wind statistics in the course of 2003 to 2013 was utilized to determine and analyze the wind speed. The average wind speed was $3.4 \mathrm{~m} / \mathrm{s}$ in July and the minimum speed was $2.5 \mathrm{~m} / \mathrm{s}$ in September. The average wind speed throughout the year was $2.95 \mathrm{~m} / \mathrm{s}$. The location of Rodan's solid waste landfill is shown in Figure 1.

Waste qualitative analysis

The percentage of the waste compositions are variable based on the region, economic and social conditions of the people, the geographic location, climate, seasons, and the waste recovery rate (legal or illegal) (2). Therefore, in order to achieve an accurate evaluation, a separate analysis of the solid waste in every region is needed throughout the course of the various seasons. The important fact is that the solid waste produced in various regions of a city

Table 2. The characteristics of the Rodan landfill

\begin{tabular}{lll}
\hline Parameter & Value & Unit \\
\hline Year of the operation start & 2009 & Year \\
Year of the operation shutdown & 2019 & Year \\
$\begin{array}{l}\text { Calculate the operation shutdown } \\
\text { model? }\end{array}$ & No & - \\
Methane production rate $(\mathrm{K})$ & 0.05 & Year $^{-1}$ \\
Methane production potential $\left(\mathrm{L}_{0}\right)$ & 170 & Ton per cubic meter \\
Concentration of NMOCs & 4000 & ppmv as hexane \\
Methane components & 50 & $\%$ by volume \\
\hline
\end{tabular}

Table 3. The average precipitation in the range of 2003 to 2013

\begin{tabular}{lccccccccccccc}
\hline Title & \multicolumn{1}{c}{ Month } \\
\cline { 2 - 11 } & March & April & May & June & July & August & September & October & November & December & January & February \\
\hline $\begin{array}{l}\text { The average of total } \\
\text { precipitation }(\mathrm{mm})\end{array}$ & 15 & 1 & 0.5 & 0.5 & 2.2 & 0.02 & 0 & 3.1 & 6.4 & 3.4 & 54 & 7.3 \\
\hline
\end{tabular}

Source: Reference 13.

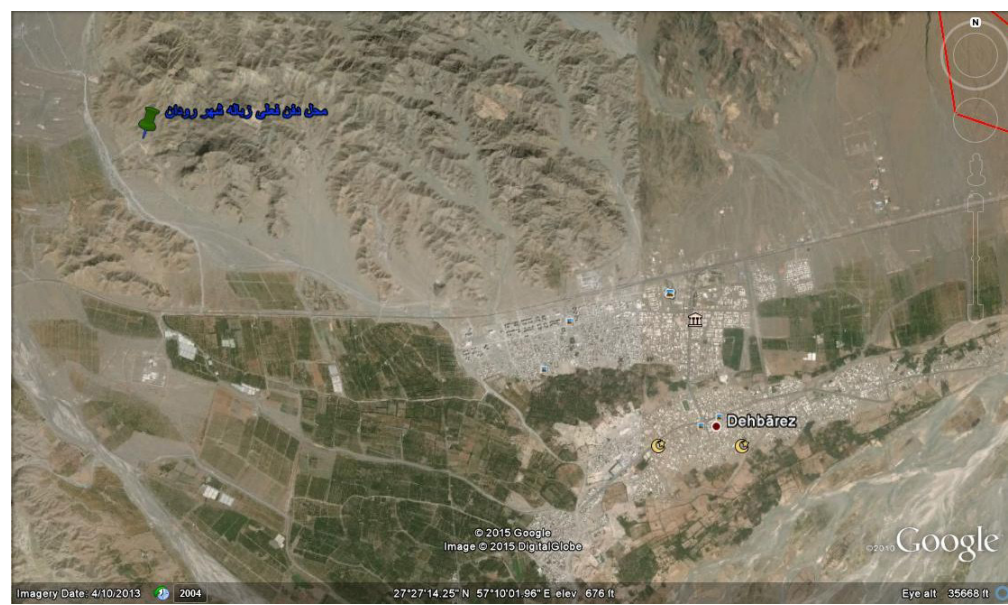

Figure 1. A satellite picture of Rodan's solid waste landfill. 
could have significant differences in respects to their composed material. Table 4 illustrates the average percentage weight of different fraction of the wastes in Rodan. As it is presented, the perishable organic components account for $24.18 \%$ of the entire wastes in the city. Plastic and rubber constitute $28.07 \%$ of this city wastes. Paper and glass constitute $8.26 \%$ and $6.05 \%$ of the wastes, respectively. Hence, the application of the recycling process in this city could result in the recovery of a large portion of plastic, rubber, paper, cardboard, metal and glass. The humidity of the waste has also been estimated to be $16.53 \%$.

\section{The waste production quantity}

The Rodan's landfill was established in 2009 and is still under operation until 2019. After the closure, a new site will be selected based on the general waste plan studies. Studies reveal that the annual waste production rate in Rodan is $402 \mathrm{~g} /$ capita/day. The annual waste production rate is illustrated in Table 5. Based on Table 5, 54824 tons of waste is disposed in this landfill in the course of 10 years of operation.

\section{The production of biogas}

Biogas is a mixture of carbon dioxide, methane and NMOCs. The rate of the produced biogas is dependent on the volume of the disposed waste in the landfill. LandGEM software has been introduced as an appropriate model to estimate the rates of biogases production such as carbon dioxide, methane and NMOCs. Hajbagheri et al (5) showed that the LandGEM software is a reliable

Table 4. The average weight percentage of the waste components in Rodan

\begin{tabular}{lc}
\hline Type & Percentage of the components \\
\hline Perishable organic compounds & 24.18 \\
\hline Paper, cardboard and box file & 8.26 \\
\hline Plastic and rubber & 28.07 \\
Glass & 6.05 \\
\hline Metal & 3.85 \\
\hline Bones & 1.65 \\
\hline Textile & 13.76 \\
\hline Wood & 8.81 \\
\hline Apartment waste & 4.95 \\
\hline Others & 0.42 \\
\hline
\end{tabular}

and appropriate tool for the purpose of estimating a wide range of gaseous compounds (5). As it is shown in Figure 2 , the produced biogas is increased through the rise of the disposed waste mass. After the landfill closure in 2019, the waste production would be decreased but not ceased. Based on our calculation, the biogas production would continue for 150 years after the operation shutdown until 2169. The maximum biogas production in the landfill after the closure is achieved in 2020 which is equal to 420 tons per year. It is necessary to prevent the emission of NMOCs into the atmosphere because biogases contain little amounts of these gases which are toxic and carcinogenic (2). Presently, the Rodan landfill lacks any biogas extraction equipment. Thus, it is essential to design such

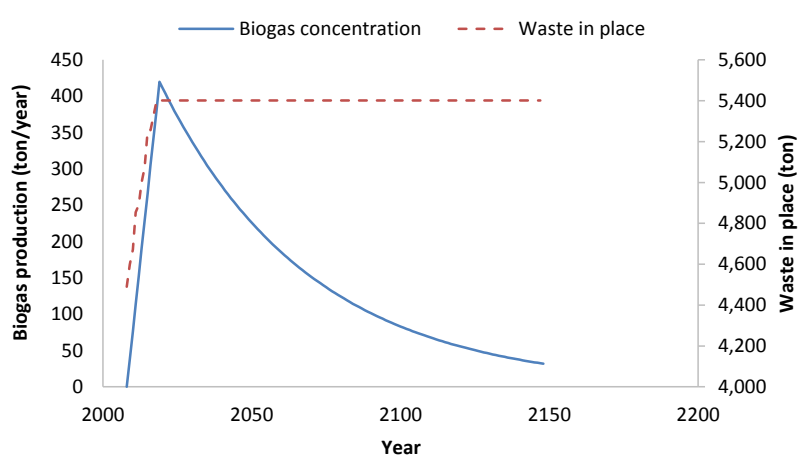

Figure 2. Amount of biogas production in Rodan's landfill between 2009 and 2169.

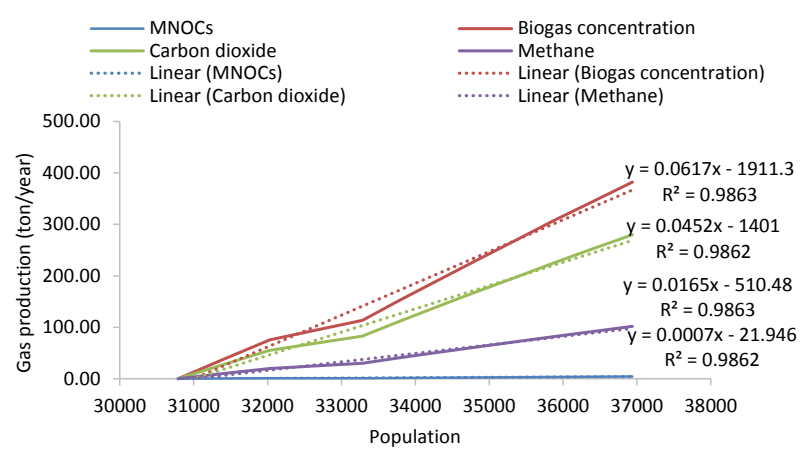

Figure 3. The relationship between population and gas production rate in the Rodan's landfill.

Table 5. The population of Rodan and the waste production rate during 2009 to 2019

\begin{tabular}{lllll}
\hline Year & Population & $\begin{array}{l}\text { Weight of the produced waste } \\
\text { (ton/day) }\end{array}$ & $\begin{array}{l}\text { Weight of the produced waste } \\
\text { (ton/year) }\end{array}$ & $\begin{array}{l}\text { Waste production rate } \\
\text { (g/capita/day) }\end{array}$ \\
\hline 2009 & 30789 & 12.3 & 4490 & 399 \\
\hline 2010 & 31404 & 12.6 & 4599 & 401 \\
\hline 2011 & 32032 & 12.8 & 4672 & 399 \\
\hline 2012 & 33285 & 13.3 & 4855 & 399 \\
\hline 2013 & 33784 & 13.4 & 4891 & 396 \\
\hline 2014 & 34291 & 13.7 & 5000 & 398 \\
\hline 2015 & 34805 & 13.9 & 5074 & 400 \\
\hline 2016 & 35327 & 14.4 & 5256 & 407 \\
\hline 2017 & 35857 & 14.4 & 5256 & 401 \\
\hline 2018 & 36395 & 14.6 & 5329 & 401 \\
\hline
\end{tabular}


system.

Figure 3 presents the relationship between the population and the total biogas, carbon dioxide, methane and NMOCs production rates. The presented relation could be utilized in estimating the produced gases in the landfill.

\section{Carbon dioxide and methane production}

Carbon dioxide and methane are among the important greenhouse gasses. Carbon dioxide is a colorless and odorless gas which plays a vital role in sustaining life on earth. The average concentration of carbon dioxide in the atmosphere is approximately $0.00756 \mathrm{~g} / \mathrm{m}^{3}$. Volcanoes and hot water springs are the natural sources of carbon dioxide. Although in comparison to manmade sources, their capacity is very limited. Microorganisms are capable of producing carbon dioxide through anaerobic and aerobic processes (Eqs. 4 and 5). However methane is only produced through anaerobic processes of organic matter decomposition by microorganisms.

$$
\begin{aligned}
& \text { Organic compounds }+\mathrm{O}_{2} \stackrel{\text { Aerobic microorganisms }}{\longrightarrow} \mathrm{CO}_{2}+\mathrm{H}_{2} \mathrm{O} \\
& \text { Organic compounds } \stackrel{\text { Aerobic microorganisms }}{\longrightarrow} \mathrm{CO}_{2}+\mathrm{CH}_{4}+\mathrm{H}_{2} \mathrm{O}
\end{aligned}
$$

This study revealed that high levels of methane and carbon dioxide are released into the atmosphere from the Rodan's landfill (Figure 4). Omrani et al (8) illustrated that $60 \%$ of the produced biogas in the landfills of Shiraz was methane which would be financially beneficial if extracted. They have also carried out a study by using the LandGEM software which illustrated that the emission rate of methane from the landfills of Shiraz is equal to $24 \mathrm{~m}^{3} / \mathrm{y}$ (8). The emission rate of carbon dioxide of Rodan's landfill from 2009 to 2169 is presented in Figure 3. As it is shown, the production and emission rate of carbon dioxide and methane is increased with the increase of the disposed waste in the landfill which would reach its maximum in 2020, a year after shutdown. In 2020, the carbon dioxide and methane production rates will be equal to 308 and 112 tons respectively. Although, it is often suggested to convert the produced carbon dioxide into biomass by algae and utilize it as raw material for biodiesel, however none of the proposed methods are financially cost effective (14). Based on our calculations, after 11 years of operation, the Rodan's landfill would emit 1537 tons of carbon dioxide and 560 tons of methane into the atmosphere. Presently, the cost of every ton of liquid carbon dioxide is 12 dollars. Thus revenue of 18444 is achievable after 11 years of operation by selling the carbon dioxide. It is worth mentioning that the initial costs for equipment and purification must also be considered in decision making. However due to the existence of ample impurities in the produced biogas, the cost of purification will appear to be very high.

Methane accommodates more utilization methods when compared to carbon dioxide. One of these is energy production. Approximately $0.00165 \mathrm{MW}$ of energy is achievable per every cubic meter of methane. It is estimated that throughout the years of operation, the Rodan's landfill would produce only $1 \mathrm{MW}$ of energy. No energy recycling approach is proposed for this landfill since the electric charge produced in this landfill is significantly low. It is proposed to burn the produced methane in order to inhibit the emission.

\section{The Production of NMOCs}

The NMOCs are the collection of chemical compounds with different chemical structure but with similar behavior in the atmosphere. NMOCs are produced and emitted from wide range sources such as burning, solvents, anaerobic decomposition of organic compounds and production stages $(11,13)$. NMOCs could also result in the formation of tropospheric ozone which poses much health risks for humans. Several other NMOCs including benzene or 1.3 Butadiene are also highly dangerous for humans $(14,15)$. Large portions of the NMOCs are among the volatile organic compounds (VOCs) which are highly dangerous. The production rate of NMOCs within the years of 2009 and 2169 are presented in Figure 5. As shown in Figure 5, the levels of NMOCs are increased with the increase in the disposal rate of waste in the landfill of Rodan. However, after 1 year of landfill closure, the production rate of NMOCs would significantly decline. The climax of NMOCs production rate is observed in the year 2020 which is one year after the shutdown and 4.82 tons of these compounds are released into the atmosphere. Although the levels of NMOCs in the atmosphere are very small, its inhibition is highly essential due to its high toxicity.

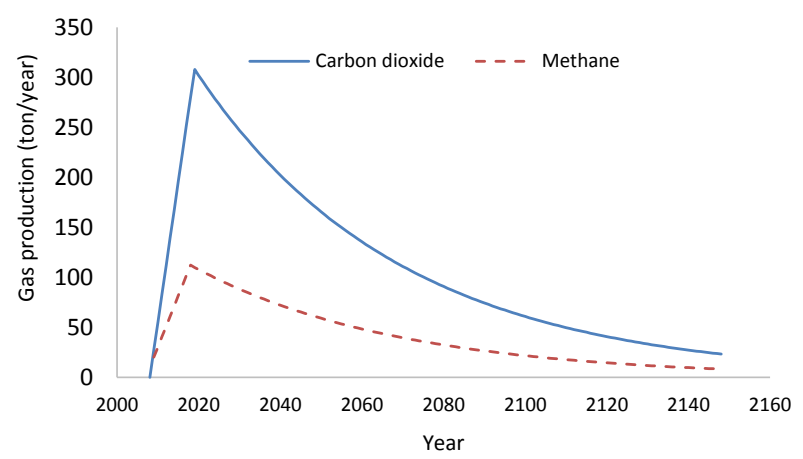

Figure 4. The carbon dioxide and methane production rates in 2009 to 2169

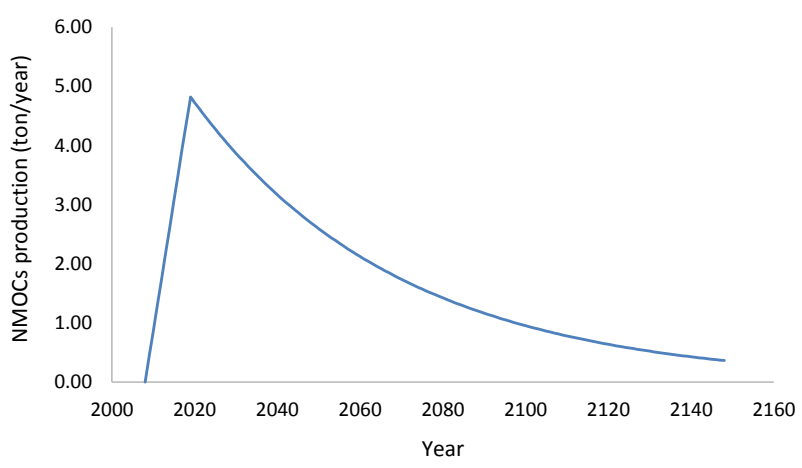

Figure 5. The NMOCs production rate within the years of 1387 to 1527. 
Table 6. The emission rate of NMOCs in 2016 in the landfill of Rodan

\begin{tabular}{|c|c|c|c|}
\hline Gas/Pollutant & $\begin{array}{l}\text { Emission rate } \\
\text { (ton/year) }\end{array}$ & Gas/Pollutant & $\begin{array}{l}\text { Emission rate } \\
\text { (ton/year) }\end{array}$ \\
\hline Total landfill gas & 266.8 & Dichlorobenzene - (HAP for para isomer/VOC) & 0.000274 \\
\hline Methane & 71.2 & Dichlorodifluoromethane & 0.017190 \\
\hline Carbon dioxide & 195.5 & Dichlorofluoromethane - VOC & 0.002378 \\
\hline NMOCs & 3.063 & Dichloromethane (methylene chloride) - HAP & 0.010570 \\
\hline 1,1,1-Trichloroethane (methyl chloroform) - HAP & 0.000569 & Dimethyl sulfide (methyl sulfide) - VOC & 0.004306 \\
\hline 1,1,2,2-Tetrachloroethane - HAP/VOC & 0.001641 & Ethane & 0.237800 \\
\hline 1,1-Dichloroethane (ethylidene dichloride) - HAP/VOC & 0.002111 & Ethanol - VOC & 0.011060 \\
\hline 1,1-Dichloroethene (vinylidene chloride) - HAP/VOC & 0.000172 & Ethyl mercaptan (ethanethiol) - VOC & 0.001270 \\
\hline 1,2-Dichloroethane (ethylene dichloride) - HAP/VOC & 0.000361 & Ethylbenzene - HAP/VOC & 0.004340 \\
\hline 1,2-Dichloropropane (propylene dichloride) - HAP/VOC & 0.000181 & Ethylene dibromide - HAP/VOC & 0.000002 \\
\hline 2-Propanol (isopropyl alcohol) - VOC & 0.026710 & Fluorotrichloromethane - VOC & 0.000928 \\
\hline Acetone & 0.003613 & Hexane - HAP/VOC & 0.005054 \\
\hline Acrylonitrile - HAP/VOC & 0.002971 & Hydrogen sulfide & 0.010900 \\
\hline Benzene - No or Unknown Co-disposal - HAP/VOC & 0.001319 & Mercury (total) - HAP & 0.000001 \\
\hline Benzene - Co-disposal - HAP/VOC & 0.007635 & Methyl ethyl ketone - HAP/VOC & 0.004550 \\
\hline Bromodichloromethane - VOC & 0.004513 & Methyl isobutyl ketone - HAP/VOC & 0.001691 \\
\hline Butane - VOC & 0.002582 & Methyl mercaptan - VOC & 0.001069 \\
\hline Carbon disulfide - HAP/VOC & 0.000392 & Pentane - VOC & 0.002116 \\
\hline Carbon monoxide & 0.034850 & Perchloroethylene (tetrachloroethylene) - HAP & 0.005452 \\
\hline Carbon tetrachloride - HAP/VOC & 0.000005 & Propane - VOC & 0.004310 \\
\hline Carbonyl sulfide - HAP/VOC & 0.000262 & t-1,2-Dichloroethene - VOC & 0.002412 \\
\hline Chlorobenzene - HAP/VOC & 0.000250 & Toluene - No or Unknown Co-disposal - HAP/VOC & 0.031930 \\
\hline Chlorodifluoromethane & 0.000999 & Toluene - Co-disposal - HAP/VOC & 0.139200 \\
\hline Chloroethane (ethyl chloride) - HAP/VOC & 0.000745 & Trichloroethylene (trichloroethene) - HAP/VOC & 0.003269 \\
\hline Chloroform - HAP/VOC & 0.000032 & Vinyl chloride - HAP/VOC & 0.004054 \\
\hline Chloromethane - VOC & 0.000538 & Xylenes - HAP/VOC & 0.011320 \\
\hline
\end{tabular}

The LandGEM software is capable of calculating the emission rate of 48 chemical compounds in NMOCs collection. The calculation results are presented in Table 6 . Based on this table, the emission rate of compounds such as vinyl chloride and benzene in the atmosphere are estimated to be 0.004 and 0.011 tons respectively in 2016. Aspiration of high concentrations of vinyl chloride in low intervals would result in negative effects on the central nervous system which is followed by symptoms such as vertigo, insomnia and headache. Low levels of vinyl chloride can dissolve in surface and underground water sources which could enter the human digestion system. Prolonged contact with low concentration of vinyl chloride by aspiration or digestion could damage the liver. The aspiration of vinyl chloride would increase the risk of liver cancer. Thus, the USEPA has classified vinyl chloride as carcinogenic compounds. Reports of the destructive effects of vinyl chlorides on the human reproduction system have also been provided (16). Although, various epidemiological studies have confirmed the relation of vinyl chloride with birth defects, however several other studies found no such connection (17). Several other studies have also confirmed that men who were in contact with vinyl chloride at works have faced abortion (16). However, various other studies have denied such connection. Studies report a reduction in fertility in mouse that was exposed to low quantities of vinyl chloride in the course of 12 months (16). The halflife of vinyl chloride in the atmosphere is only a few hours, however, in the case of wind blow; this harmful substance can be transmitted across the nearby areas which could pose threat for the residents of those areas. The contact of vinyl chloride with the human body would demand a concentration of $1.3 \mathrm{mg} / \mathrm{m}^{3}$. Otherwise it could pose serious threat to human health as it was mentioned that the compounds such as vinyl chloride have serious consequences for human body. Thus the inhibition and control of this substance is highly significant in Rodan's landfill. Majority of the compounds in Table 6 are members of VOCs and hazardous air pollutants $(\mathrm{PAH})$ which are indicated in the table.

The modeling of the pollutants emission in the atmosphere

In this section, the total biogas transmittance of carbon dioxide, methane and NMOCs in the atmosphere is modeled in the direction of the wind using Screen View software. Figure 6 presents the total concentration of biogases in the nearby atmosphere of the Rodan's landfill. As it is shown, the concentrations of both pollutants would reach their maximum within the distance of $200 \mathrm{~m}$. The concentration of the total biogas and carbon dioxide within the distance of $200 \mathrm{~m}$ of the landfill is equal to 202580 and $10430 \mu \mathrm{g} / \mathrm{m}^{3}$. The total concentration of the biogas and carbon dioxide would decrease by taking the distance from the landfill in such a way in which it would reach 3507 and $2534 \mu \mathrm{g} / \mathrm{m}^{3}$ respectively within the distance of $100 \mathrm{~m}$. Since the average concentration of carbon dioxide in the atmosphere is $7560 \mu \mathrm{g} / \mathrm{m}^{3}(14)$, the produced car- 


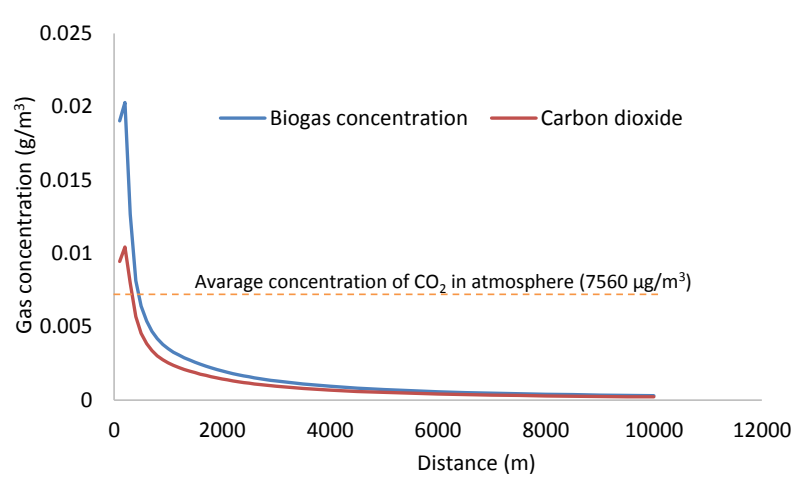

Figure 6. Total biogas emission and carbon dioxide in the vicinity of the landfill of Rodan in the direction of the wind.

bon dioxide in the landfill could reach 17990 and 10097 $\mu \mathrm{g} / \mathrm{m}^{3}$ respectively within the distance of 200 and $1000 \mathrm{~m}$. This implies that within the distance of $200 \mathrm{~m}$ of the landfill, the concentration of the carbon dioxide which is 2.3 and is within its normal levels, would reach the concentration of 1.3 within the distance of $1000 \mathrm{~m}$.

The emitted methane from the landfill has similar conditions to carbon dioxide. The maximum concentration of gas which is equal to $306 \mu \mathrm{g} / \mathrm{m}^{3}$ is reached within the distance of $200 \mathrm{~m}$. The concentration of methane would reach $94.41 \mu \mathrm{g} / \mathrm{m}^{3}$ when the distance is increased over $1000 \mathrm{~m}$ and within the distance of $10000 \mathrm{~m}$, it would be reduced to $7.92 \mu \mathrm{g} / \mathrm{m}^{3}$. Methane is considered as a gas with greenhouse properties. The heating capacity of methane is 25 times stronger than carbon dioxide thus the inhibition of this gas is of significant importance. Generally, the effects of methane on human health are through the replacement of oxygen and lowering of its concentration $(19,20)$. Headaches, vertigo and nausea are the symptoms of high concentration of methane in the breathing air. However based on the conducted calculations, the concentration of methane around the landfill of Rodan is not high enough to pose any threats for human health (Figure 7).

The NMOCs include dangerous substances such as vinyl chloride. Thus determining their concentrations in the vicinity of the landfill is of great importance. As it is presented in Figure 8, the highest level of concentration which is equal to $12.46 \mu \mathrm{g} / \mathrm{m}^{3}$ is observed in the distance of $200 \mathrm{~m}$ from the landfill. By taking the distance from the landfill, the concentration of NMOCs would decrease, which would reach a concentration of $3.75 \mu \mathrm{g} / \mathrm{m}^{3}$ in the distance of $1000 \mathrm{~m}$. The concentration of NMOCs in the distance of $10000 \mathrm{~m}$ from the landfill would be equal to only $0.32 \mu \mathrm{g} / \mathrm{m}^{3}$.

\section{Conclusion}

In this study, we investigated the production and emission of carbon dioxide, methane and 48 NMOCs in the landfill of Rodan by using the LandGEM software. We have also modeled the transmittance of the produced pollutants in the nearby areas of the landfill by using the Screen View software. The results suggested that the maximum gas production in the landfill would be achieved one year

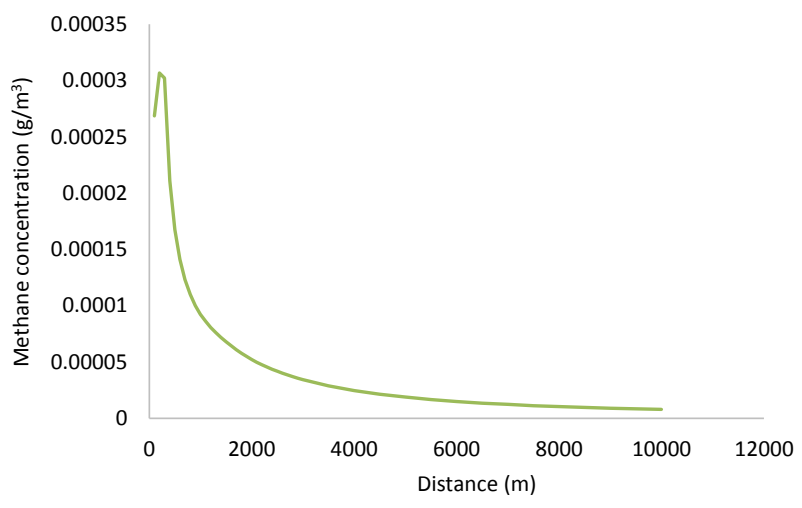

Figure 7. The transmittance of methane around the landfill of Rodan in the direction of the wind.

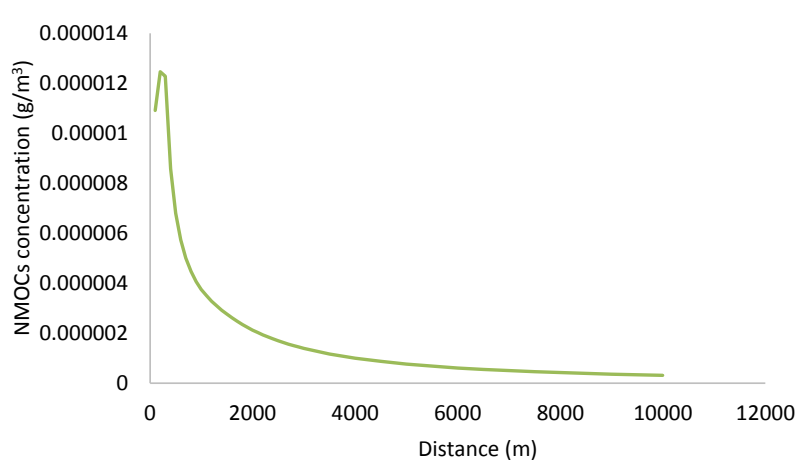

Figure 8. The concentration of NMOCs within various distances from the landfill in the direction of the wind.

after the operation shutdown which is in the year 1398. In this year, the production rate of carbon dioxide, methane and NMOCs would be equal to 308, 112 and 4.82 ton per year respectively. The results have also suggested that this landfill would only have the capacity for $1 \mathrm{MW}$ of energy production due to the triviality of the methane production in the course of 11 years of operation. Thus it is suggested to incinerate the produced gas in order to protect the environment and inhibit the greenhouse property. Based on our calculations, the concentration of carbon dioxide, methane and NMOCs would be equal to 94.41, 10097 and $3.75 \mathrm{mg} / \mathrm{m}^{3}$ respectively within the distance of $1000 \mathrm{~m}$ from the landfill. The concentration of carbon dioxide within the distance of $1000 \mathrm{~m}$ is 1.3 which is equal to the universal standard. The results obtained in this study could be used for the purpose of design and installation of extraction or incineration equipment in the landfill of Rodan.

\section{Ethical issues}

Authors are aware of, and comply with, best practice in publication ethics specifically with regard to authorship (avoidance of guest authorship), dual submission, manipulation of figures, competing interests and compliance with policies on research ethics. Authors adhere to publication requirements that submitted work is original and has not been published elsewhere in any language. 


\section{Competing interests}

The authors declare that there is no conflict of interest that would prejudice the impartiality of this scientific work.

\section{Authors' contribution}

All authors of this study have a complete contribution for data collection, data analyses and manuscript writing.

\section{References}

1. Porahmad A, Habibi K, Zahraee S, Nazariadli M. Using phase algorithm for relocating of municipal equipment (case study: Babolsar landfill). Environment Journal 2008; 42: 31-42. [In Persian].

2. Jonidi Jafari A, Talaiekhozani A. Introduction to Solid Waste Material. 1st ed. Tehran: Ebadifar; 2011. [In Persian].

3. Poralaghebandan H, Shahsavari A, Hamsizadeh A, Sami S. Municipal Solid Waste Engineering. 1st ed. Tehran: Press the municipalities and the village administrations of Iran; 2010. [In Persian].

4. Zoghi M, Ghavidel A. Prediction of methane percentage in landfills by using artificial neural networks. Iranian Journal of Health and Environment 2009; 2(2): 140-9. [In Persian].

5. Hajbagheri H, Safari A, Yavri A. Introducing of LandGEM model for estimation of emitted biogas from landfill and its effective parameters. The First Conference of New Clean Energy; Hamedan, Iran.

6. Talaiekhozani A, Bagheri M, Rostami Najafabadi N, Borna E. Effect of nearly one hundred percent of municipal solid waste recycling in Najafabad city on improving of its air quality. Journal of Air Pollution and Health 2016; 1(2): 11122.

7. Safari E, Asadollahfardi GR, Joghtaee F. Evaluation of reducing possibility of produced methane pollution in municipal landfill based on sustainable development mechanism in Rasht city. Forth National Congress on Waste Management; Mashhad; 2010.

8. Omrani GA, Mohseni N, Haghighat K, Javid AH. Technical and sanitary assessment of methane extraction from Shiraz landfill. Journal of Environmental Science and Technology 2009; 10(4): 175-82. [In Persian].

9. Mahvi A, Rodbari A. Calculation of methane emission from Shahrod landfill by using LandGEM software. Fifth Conferences of Solid Waste Management; April 22-23, 2010; Mashhad, Iran.

10. Mahdipour A, Sekhavatjo M, Neisi A, Takdastan A.
Estimation of gas production from municipal solid waste landfills by using LandGEM software (case study of Ahwaz, Dezfol, Abadan and Khoramshahr). The fifith National Conference and Exhibition on Environmental Engineering; Tehran; November 11-14, 2011. [In Persian].

11. Talaiekhozani A. Landfill Gas Emissions Model (LandGEM) Version 3.02 User's Guide (internet); 2015 (cited 2016 January 8) Available from Netlibrary: http:// www.researchgate.net/publication/282943665_3 3.02 doi: $\quad 10.13140 /$ RG.2.1.4758.3442.

12. Maliva R, Missimer T. Aridity and drought. In: Maliva R, Missimer T, eds. Arid lands Water Evaluation and Management. Berlin Heidelberg: Springer; 2012. p. 21-39.

13. Talaiekhozani A, Bagheri M, Goli A, Talaei Khozani MR. An overview of principles of odor production, emission, and control methods in wastewater collection and treatment systems. J Environ Manage 2016; 170: 186-206. doi: $\quad 10.1016 /$ j.jenvman.2016.01.021.

14. Roshan A, Talaiekhozani A, Roodpeyma Sh. A Review on Removal of Pollutants from Air Using Biological Methods. The $5^{\text {th }}$ Conference on Application of Chemistry in Novel Technology. Isfahan. Iran. December 17, 2015. doi: 10.13140/RG.2.1.4239.1288.

15. Alaee S, Talaiekhozani A, Ziaee GR, Lohrasbi P. Evaluation of Iranian college students' awareness about infertility risk factors. Jundishapur J Health Sci 2016; 8(2): e34172. doi: 10.17795/jjhs-34172.

16. Alaee S, Talaiekhozani A, Rezaei S, Alaee K, Yousefian E. Cadmium and male infertility. Journal of Infertility and Reproductive Biology 2014; 2(2): 62-9.

17. Agency for Toxic Substances and Disease Registry (ATSDR). Toxicological Profile for Vinyl Chloride (Update). Atlanta, GA: Public Health Service, U.S. Department of Health and Human Services; 1997.

18. Agency for Toxic Substances and Disease Registry (ATSDR). Case Studies in Environmental Medicine. Vinyl Chloride Toxicity. Atlanta, GA: Public Health Service, U.S. Department of Health and Human Services; 1990.

19. Talaiekhozani A, Masomi B, Hashemi SMJ. Evaluation of Gaseous Pollutants Emission Rate from Marvdasht Landfills. Journal of Advanced Medical Sciences and Applied Technologies 2016; 2(1): 162-75.

20. I.R. OF Iran Meteorological Organization. Weather Station Rudan; 2016 [cited 2016 Jan 10]. Available from: http:// www.irimo.ir/eng/wd/701-Weather-Forcast-Rudan. html?id=132. 